\title{
Report on the Sixth International Symposium on Temperature
}

\author{
B. W. Mangum* and G. T. Furukawa* \\ National Bureau of Standards, Washington, DC 20234
}

July 6, 1982

\begin{abstract}
This is a report on the Sixth International Symposium of Temperature which was held in Washington, DC, USA, March 15-18, 1982. Included is a brief introduction discussing the timeliness of the symposium, its sponsors, and the publication of the proceedings. The remainder of the report is devoted to $\sigma$ summary of the Plenary and Technical sessions of the symposium.
\end{abstract}

Key words: fixed points, temperature scale; thermometers; thermometry; symposium.

\section{Introduction}

The Sixth International Symposium on Temperature was held in Washington, DC, March 15-18, 1982. The five preceding symposia on Temperature were in 1971, $1961,1954,1939$, and 1919 . The symposium in 1919 was held in Chicago and called the Symposium on Pyrometry. The symposia in 1939 and in 1954 were held in New York City and in Washington, DC, respectively; the fourth symposium was held in Columbus, Ohio in 1961; the fifth symposium was held in Washington, DC in 1971. Except for the Symposium on Pyrometry, the proceedings of these symposia have been published under the title Temperature: Its Measurement and Control in Science and Industry.

The sixth symposium was co-sponsored by the American Institute of Physics, the Instrument Society of America, and the National Bureau of Standards (NBS).

This symposium was held at a propitious time, coming just prior to the meeting of the Comite Consultatif de Thermométrie (CCT) on 30 March to 1 April 1982, during which that body deliberated on possible improvements in and extension of the International Practical Temperature Scale of 1968 (IPTS-68), deliberations which may lead to a new Scale in 1987. The symposium provided a forum for discussion of new developments in thermometry, as well as for reviews of the current situation. It brought to a focus the current research and results of many efforts in thermometry and revealed the areas where more work is needed, as well as areas which are now well in hand. Concomitantly, various problems with the IPTS-68 (non-agreement with thermodynamic temperatures, extension of the temperature range, adequacy of defining fixed points,

*Center for Absolute Physical Quantities, National Measurement Laboratory. standard interpolating instruments, etc.) were addressed which should assist the members of the CC'T in devising a new and more comprehensive scale. Considering the enormous amount of work in thermometry, it is not surprising that there were some duplications at the symposium. Certain duplications are desirable, of course.

There were approximately 1200 registrants from 20 countries at the symposium and the exhibits, with about 480 symposium attendees. This was the first temperature symposium at which there were commercial exhibits of temperature equipment. Three hundred persons attended just to see the exhibits, approximately 90 in number.

The principal areas of thermometry covered at the symposium were: thermodynamic temperature measurements and temperature scales, temperature fixed points, spectroscopic (rotational, vibrational, NMR) and radiation thermometry, electronic thermometry, vapor pressure thermometry, resistance thermometry, thermocouple thermometry, medical thermometry, instrumentation, automation, and calibration.

\section{The Proceedings}

The papers presented at the symposium are scheduled for publication in September 1982 in Temperature: Its Measurement and Control in Science and Industry (American Institute of Physics, New York, 1982), Vol. 5. The editor of that publication is James $F$. Schooley of NBS, who was also the program chairman.

\section{The Plenary and Technical Sessions}

\section{A. Plenary Session}

At the Plenary session, the conference was opened by the conference's General Chairman, Lawrence G. 
Rubin, of the National Magnet Laboratory, MIT, USA, who, in his brief introductory remarks, welcomed the attendees and wished them a fruitful meeting. He then introduced H. Preston-Thomas, of the National Research Council (NRC), Ottawa, Canada, who, in turn, introduced the keynote speaker, Ralph P. Hudson, of the International Bureau of Weights and Measures (BIPM), Sevres, France. Hudson's address was entitled, "Temperature Scales, the IPTS, and its Future Development."

In his remarks, Hudson gave a brief review of the basic concepts of internationally-agree-upon temperature scales, of events leading to the International Practical Temperature Scales (IPTS), and of the practical considerations which influence their construction and use. He mentioned some semi-official scales which are widely used in certain temperature ranges and discussed in detail the IPTS-68, the latest version of the IPTS, and its presently-perceived deficiencies. He indicated some of the ways in which the IPTS-68 could possibly be improved and extended in the near future, in the form of a new scale going to temperatures substantially lower than that of the IPTS-68. Some new primary thermometry data and instrumentation which will probably form the basis for constructing that revised scale were reviewed. The advantages and disadvantages of the prescribed standard instruments of the IPTS-68, including their temperature regions of use, were also discussed; some likely candidates for interpolation instruments for the revised scale and their possible ranges of utility were described in some detail. The desirability of removing the standard thermocouple from any future scale definition was documented. In his concluding remarks, the speaker briefly addressed the relationship between state-of-the-art metrology and the requirements of science and industry and some of the possible consequences of revising the scale.

Throughout his talk, Hudson pointed out some specific papers to be presented at the symposium which concerned thermodynamic temperature measurements and/or temperature scale work which he considered to be particularly timely and relevant to discussions of a new scale. The subject of the keynote address was itself very timely in that it put the various aspects of temperature scales in their proper perspective. This talk thus set the stage for the entire symposium.

\section{B. Technical Sessions}

Immediately following the keynote address, the technical sessions convened. There were 181 technical papers presented at the symposium, distributed among 33 technical sessions, three or four parallel sessions at a time. In addition, two afternoon sessions were devoted entirely to approximately 15 Manufacturer's Application Papers, and manufacturers' exhibits were open three afternoons for the benefit of the participants. In order to get comments from the symposium participants concerning temperature scales, the CCT held an open meeting on the last afternoon of the symposium.

A brief summary of the work reported at the technical sessions follows.

\section{Fundamental Thermometry and Temperature Scales}

Although direct and simple methods for accurate realization of thermodynamic temperatures remain about as elusive as ever, the review of the measurement of thermodynamic temperature by L.A. Guildner (NBS, USA) et el. showed that remarkable improvements in every technique have occurred in the eleven-year period since the fifth symposium. While gas thermometry retained superiority in accuracy except at the extremes of temperature, measurements by noise thermometry, acoustic thermometry, total- and spectral-radiation thermometry, and dielectric constant gas thermometry have reached a sufficiently high level of reliability to either stand by themselves or to improve our confidence in gas thermometer results.

H. Marshak (NBS, USA) presented details of work on thermodynamic thermometry using gamma-ray anisotropy. This method permits thermodynamic temperature measurement by the only technique currently feasible in the very lowest range, potentially from a few microkelvins to about $1 \mathrm{~K}$, with an uncertainty of no more than a few percent. Marshak reported that results of noise-thermometer measurements agreed with his ${ }^{60} \mathrm{Co}$ gamma-ray anisotropy results to within $0.5 \%$ in the temperature range from 0.01 to $0.05 \mathrm{~K}$.

The gas thermometry which sets the standard for thermodynamic temperatures from 2.6 to $27.1 \mathrm{~K}$ was performed at the National Physical Laboratory (NPL), UK, by $K$. H. Berry. He summarized that work and compared the resulting practical scale, NPL-75, with the IPTS-68, $\mathrm{T}_{58}\left({ }^{4} \mathrm{He}\right.$ vapor pressure scale), and $\mathrm{T}_{\mathrm{XISU}}$ (the Iowa State Magnetic scale). Berry's work has been confirmed by other measurements, some of which were presented at the symposium.

D. Gugan, et al. (Bristol Univ., UK) discussed dielectric constant gas thermometry (DCGT) which, while nominally gas thermometry, depends on the change of the dielectric constant with gas density and, thus, is intensive in nature, in contrast to the extensive quality of regular gas thermometry. This method appears unusually attractive for its simplicity and high accuracy. With this very different approach, Gugan reported values 
within $0.3 \mathrm{mK}$ of Berry's results over the range from 4.2 to $27 \mathrm{~K}$.

Gugan also discussed a re-analysis of his DCGT isotherm data and of Berry's constant volume gas thermometry (CVGT) isotherm results using a procedure known as surface-fitting. This is a procedure in which all the data from the isotherms are combined and then the isotherm temperatures and the functional forms of the virial coefficients are determined simultaneously from a single, weighted, least-squares fit. He substantiated the accuracy and smoothness of NPL-75 but the re-analysis suggests that the values assigned to Berry's isotherm temperatures need corrections of a few tenths of a millikelvin. The re-analysis also showed that DCGT is a good technique, that it is rather insensitive to details of analysis, and that its internal consistency is easy to examine. This fitting technique also showed the necessity of using the third virial coefficient for proper analysis of CVGT data.

Measurements by acoustic thermometry have been made at the NPL, UK, in the low-temperature range by A. R. Colclough. He summarized the theory and practice of acoustic thermometry, which as executed by him yielded results agreeing with Berry's values to within $1 \mathrm{mK}$ over the range from 4.2 to $20.27 \mathrm{~K}$. The one exception was a difference of $2.2 \mathrm{mK}$ at $17 \mathrm{~K}$.

The CVGT effort at the CSIRO National Measurement Laboratory (NML), Australia, was reported by W. R. G. Kemp et al., and that at the Kamerlingh Onnes Laboratory (KOL), the Netherlands, by P. P. M. Steur et al. Both of these groups of researchers used reference temperatures from NPL-75 and their results showed excellent consistency with the NPL results, from 13.8 to $27.1 \mathrm{~K}$ at the NML and from 4 to $27 \mathrm{~K}$ at the KOL.

Work is in progress to determine thermodynamic values by CVGT at higher temperatures. The KOL apparatus was designed for measurements up to $100 \mathrm{~K}$, and initial values up to $40 \mathrm{~K}$ were reported at the symposium. A constant volume gas thermometer has been built also at the National Research Laboratory of Metrology (NRLM), Japan. Using this CVGT, H. Sakurai reported preliminary measurements of the temperature of the triple point of oxygen.

H. H. Plumb (NBS, USA) presented results of analyses of acoustical isotherms at temperatures from 9 to $34 \mathrm{~K}$. He has obtained values for the ${ }^{4} \mathrm{He}$ second and third virial coefficients and they are $B=16.8925$ $383.095 / \mathrm{T}-150.665 / \mathrm{T}^{2}\left(\mathrm{~cm}^{3} / \mathrm{mol}\right)$ and $\mathrm{C}=5788 / \mathrm{T}$ $\mathrm{cm}^{6} \mathrm{~mol}^{-2}$, respectively. Plumb compared his measured isotherm slopes (i.e., the term linear in pressure) with those calculated from the second virial coefficients determined in other, non-acoustical experiments. He concluded that the close agreement of those slopes indicates the inadequacy of the generally-accepted HelmholtzKirchhoff correction, and that it is not applicable, in its predicted entirety, to the acoustical isotherm data that have been measured in the NBS acoustical thermometer.

A. R. Colclough described the refractive index thermometer that has been built and tested at the NPL, UK. He showed that the accuracy to be expected from this method should be comparable to that obtained from other methods.

M. R. Moldover (NBS, USA) et al. discussed the application of spherical resonators to the determination of the speed of sound of a gas such as argon at the zero pressure limit with estimated internal inconsistencies of $\pm 3 \times 10^{-6}$. He discussed the application of this technique for the determination of thermodynamic temperatures.

Preparations to extend the CVGT measurements at the NBS, USA, beyond the currently-reported range from 0 to $457^{\circ} \mathrm{C}$ were described by $L$. A. Guildner et al. Current activities are focused on measuring temperature values between 500 and $800{ }^{\circ} \mathrm{C}$, with an ultimate objective of measuring the thermodynamic temperature of the gold point.

R. A. Kamper (NBS Boulder, USA), in a paper entitled "Survey of Noise Thermometry" presented at the fifth temperature symposium in 1971 concluded, "Noise thermometry is and will remain a difficult and frustrating art." At that symposium there was only one other paper on noise thermometry, "Methods of Noise Thermometry above $400{ }^{\circ} \mathrm{C}$," which was presented by A. Actis et al. (IMGC, Italy). At the sixth temperature symposium, ten papers on Johnson-noise thermometry were presented in two sessions by authors from six countries: Australia, Belgium, Italy, Japan, United States, and West Germany. Those papers covered the temperature range from 0.01 to beyond $1900 \mathrm{~K}$. In a session on thermodynamic noise thermometry, R. J. Soulen et al. (NBS, USA) reported measurements of Johnson noise with Josephson junctions to determine temperatures in the range from 0.01 to $0.52 \mathrm{~K}$ with inaccuracies of \pm 0.5 to $\pm 0.2 \%$. G. Klempt (Univ. of Müinster, FRG) measured liquid helium temperatures at $2.145 \mathrm{~K}$ with a total uncertainty of $0.3 \mathrm{mK}$. C. P. Pickup (CSIRO, Australia) measured a temperature of $135^{\circ} \mathrm{C}$ with a standard deviation of $2.4 \mathrm{mK}$ for a total integration time of $5.4 \times 10^{6} \mathrm{~s}$ and showed the IPTS-68 to be $12 \mathrm{mK}$ too high. L. Crovini et al. (IMGC, Italy) measured temperatures in the range from 630 to $962^{\circ} \mathrm{C}$ with a total uncertainty of 0.18 to $0.34 \mathrm{~K}$ with an integration time of up to $9600 \mathrm{~s}$ and showed differences from IPTS- 68 of as much as $0.67 \mathrm{~K}$ at $850^{\circ} \mathrm{C}$.

Values of thermodynamic temperature at 327,344 , and $365 \mathrm{~K}$ were measured at the NPL, UK, by a total radiation thermometer. The results, reported by $T$. J. 
Quinn et al., are in good agreement with the NBS gas thermometer measurements.

The accuracy of thermodynamic temperatures measured with spectral photoelectric pyrometers has improved rapidly and can be expected to be superior to the best gas thermometry at temperatures above the gold point. Results of new measurements at the CSIRO, Australia were reported by T. P. Jones et al. for the thermodynamic values of the freezing points of silver and copper, on the basis of the IPTS-68 value for the gold point. Similarly, M. Ohtsuka et al. reported results of measurements of the copper to silver interval by a monochromatic optical pyrometer at the NRC, Canada.

R. E. Bedford et al. (NRC, Canada) presented a paper on the measurement of the melting temperature of copper-71.9\% silver eutectic, using a monochromatic optical pyrometer. The mean value for the melting temperature of the eutectic as determined from two eutectic ingots and from the freezing points of three silver ingots, was $1053.12 \pm 0.10 \mathrm{~K}$, relative to the silver point value of $1235.20 \mathrm{~K}$.

P. B. Coates et al. (NPL, UK) reviewed the progress made at the NPL on the measurement of thermodynamic temperatures above the zinc point by photon-counting radiation pyrometry. The estimated total uncertainty of the method from the zinc point to the gold point was given as $50 \mathrm{mK}$. Measurements were recently obtained on $\mathrm{Al}, \mathrm{Ag}, \mathrm{Cu}$, and $\mathrm{Pd}$ points. The preliminary value reported for the $\mathrm{Pd}$ point was 1555.3 $\pm 0.2^{\circ} \mathrm{C}$, based on the IPTS- 68 value for the Au point. Preliminary results were given for the comparison of $t_{68}$ and thermodynamic temperatures between 440 and $630{ }^{\circ} \mathrm{C}$. Preliminary values for the $\mathrm{Au}$ and $\mathrm{Ag}$ points relative to the $630^{\circ} \mathrm{C}$ reference temperature were also reported.

In view of the elaborate experimental techniques required to make accurate thermodynamic measurements, the need for a practical scale above $0.5 \mathrm{~K}$, say, remains as great as ever. As mentioned earlier, a revision of the International Practical Scale is in the offing and, this being the case, the work at the KOL to improve the helium vapor pressure equations, reported by $\mathbf{M}$. Durieux et al., is particularly timely. Also, the work at the CSIRO, reported by $R$. C. Kemp, refines the interpolating techniques first put forward by C. G. M. Kirby (NRC), and establishes a combination of choice of fixed points, form of equation and derivation of constants that reduces the non-uniqueness (variation of corresponding values given by different standard platinum resistance thermometers (SPRTs)) to a nearly uniform $0.2 \mathrm{mK}$ over the range from $13.8 \mathrm{~K}$ to $273 \mathrm{~K}$. These should be very helpful in the deliberations of the CCT.

\section{Fixed Points}

About 30 papers dealt with the realization of fixed or reference points, distributed throughout the temperature range from the superconductive transition point of $W$ at about $0.015 \mathrm{~K}$ to the melting point of $\mathrm{Ta}$ at $3258 \mathrm{~K}$.

For several years, the Office of Standard Reference Materials of the NBS (USA) has issued two superconductive fixed point devices, SRM 767, containing $\mathrm{Pb}, \mathrm{In}, \mathrm{Al}, \mathrm{Zn}$, and $\mathrm{Cd}$, and $\mathrm{SRM} 768$, containing $\mathrm{AuIn}_{2}, \mathrm{AuAl}_{2}, \mathrm{Ir}, \mathrm{Be}$, and W. To date, about $100 \mathrm{SRM}$ 767 and 50 SRM 768 devices have been issued. J. F. Schooley et al. (NBS, USA) reviewed the progress made with superconductive transition points and discussed the reproducibilities of prototypes of SRM 767 and SRM 768 devices that were issued. For 22 SRM 767 devices tested, $\mathrm{Pb}, \mathrm{In}, \mathrm{Al}, \mathrm{Zn}$, and $\mathrm{Cd}$ with transition temperatures $\left(\mathrm{T}_{\mathrm{c}}\right)$ at about $7.20,3.41,1.18,0.85$, and $0.52 \mathrm{~K}$, respectively, showed standard deviations of 0.2 , $0.2,0.4,0.4$, and $0.3 \mathrm{mK}$, respectively. For the five SRM 768 devices tested, with $T_{c}$ of the specimens ranging between 0.015 and $0.2 \mathrm{~K}$, the $T_{c}$ among samples showed measurable differences which were attributed principally to ferromagnetic impurities. Consequently, each device was calibrated against the NBS-CTS-1 and given individual $\mathbf{T}_{\mathbf{c}}$ values which were reproducible at the level of from $0.1 \mathrm{mK}$ to $0.2 \mathrm{mK}$.

Temperature values of the superconductive transition points of $\mathrm{Pb}, \mathrm{In}, \mathrm{Al}, \mathrm{Zn}$, and Cd of SRM 767 have been assigned on the 1976 Provisional $0.5 \mathrm{~K}$ to $30 \mathrm{~K}$ Temperature Scale (EPT-76) and, hence, the device provides 5 of the 11 reference points of that scale. A. E. ElSamahy (KOL, the Netherlands) et al. discussed how the transitions compared in eight different devices, three each at KOL and NPL and two at NML. The results at the KOL and NPL were correlated through common temperature scales, the NPL-75 and the $T_{X 1}$; the results at NML, obtained on the $\mathbf{T}_{\mathrm{XISU}}$ Scale, made the comparison slightly less certain, however. The spreads in the transitions for the six devices at KOL and NPL were 1.1, $0.4,0.6,1.5$, and $0.7 \mathrm{mK}$ for $\mathrm{Pb}, \mathrm{In}, \mathrm{Al}, \mathrm{Zn}$, and $\mathrm{Cd}$, respectively. If the two devices at the NML were included, the spreads increased to $1.7,0.5$, and $0.9 \mathrm{mK}$ for $\mathrm{Pb}, \mathrm{In}$, and $\mathrm{Al}$, respectively. Since single crystals of superconductive materials have been found to have sharper transitions than those of the polycrystalline materials, a suggestion was made to circulate an SRM 767 device with single crystals for comparison.

In 1978 the CCT initiated a program for international intercomparison of fixed points by means of sealed cells. F. Pavese (IMGC, Italy) summarized the results of the intercomparison of the triple points of $\mathrm{Ar}, \mathrm{O}_{2}, \mathrm{e}-\mathrm{H}_{2}$, 
$\mathrm{CH}_{4}, \mathrm{~N}_{2}, \mathrm{Ne}$, and e- $\mathrm{D}_{2}$. Eleven laboratories were involved, with varying degrees of participation, and eight or nine different cell designs were compared. The number of cells of each gas that was tested varied. The results obtained with Ar were the best, with an rms difference of $\pm 0.1 \mathrm{mK}$. Oxygen cells showed some systematic differences that require further analysis and measurements; the cells with best agreement are within $\pm 0.2 \mathrm{mK}$. Methane measurements agreed to within $\pm 0.3 \mathrm{mK}$; measurements repeated later, however, showed shifts larger than this value. Neon cells showed a small systematic difference that ranged from about \pm 0.2 to $\pm 0.4 \mathrm{mK}$. The question was raised as to whether the difference could be attributed to variations in the isotopic composition of the samples. More measurements or further analyses are required on the $\mathrm{e}-\mathrm{H}_{2}, \mathrm{e}-\mathrm{D}_{2}$, and $\mathrm{N}_{2}$ cells.

A number of reports concerned investigations of triple points of cryogenic substances (sealed in miniature pressure cells) using adiabatic cryostat techniques. Also, some triple-point measurements, obtained by using a condensation-type cryostat, were reported. Both techniques involve the measurements of equilibrium melting points at known increasing amounts of sample melted. The range of the melting points becomes narrower as the purity of the samples increases. The triple point may be taken as the average over a selected range of sample melted ( $F$ ), as the extrapolated value at $F=1$, or as the extrapolated value at $1 / F=0$. The latter value assumes that the system follows the ideal solution law, that the observations are at equilibrium, and that the impurities remain in the liquid or that the distribution coefficient of the impurities in the liquid and solid solutions can be obtained.

G. Bonnier et al. (INM, France) discussed the results of investigations of the thermal behavior of sealed cells of different shapes. A cell with compartments for five different gases, which has been used successfully in triplepoint measurements, was described.

F. Pavese et al. (IMGC, Italy) reviewed the developments made at IMGC in 10 years of research on the triple points of sealed cells, having filled about 50 cells with a dozen different substances during that time. The cells that have been built were chiefly narrow cylinders which could be readily inserted into a toploading, adiabatic cryostat. Gases that were investigated include $\mathrm{Ar}, \mathrm{O}_{2}, \mathrm{CH}_{4}, \mathrm{Ne}, \mathrm{C}_{2} \mathrm{H}_{6}$, and others.

G. T. Furukawa (NBS, USA) discussed the results of a comparison of the triple points of six sealed cells of argon, of which three were NBS cells (each of a different designt and one each was from IMGC, NRC, and NRLM. Six SPRTs were used in the study. The results of these six cells agreed to within $\pm 0.1 \mathrm{mK}$. The average triple-point value for the three NBS cells, obtained with five SPRTs, was reported to be $83.8003 \mathrm{~K}$ (S.D.= $0.017 \mathrm{mK}$ ) on the NBS-IPTS- 68 or $83.7970 \mathrm{~K}$ on the NPL-IPTS-68. The results obtained with all six SPRTs showed that their calibrations were consistent to well within the reproducibility of the argon triple point.

W. R. G. Kemp (CSIRO, Australia) reported the triple-point temperature of $e-D_{2}$ to be $18.6909 \mathrm{~K}$ and that of $n-D_{2}$ to be $18.709 \pm 0.001 \mathrm{~K}$. These values were obtained from melting-point measurements using a condensation-type adiabatic cryostat. For the $e-D_{2}$ measurements, hydrous ferric oxide was placed in the sample vessel to aid conversion of the $D_{2}$; the melting range was $0.2 \mathrm{mK}$ and the reproducibility was $\pm 0.1 \mathrm{mK}$. Nominal purity of the sample was 99.5 percent. Further measurements obtained after purification of the sample gave results which were the same as the original results. For the $n-D_{2}$ measurements, the sample chamber contained no catalyst. The melting range in this case was not as small as that obtained with the e- $D_{2}$, possibly due to some conversion from the para to the ortho state. From another experiment using the same adiabatic cryostat and method, W. R. G. Kemp et al. (CSIRO, Australia) reported the triple-point temperature of $\mathrm{Xe}$ to be $161.388 \pm 0.001 \mathrm{~K}$. The relatively broader range of melting points found for $\mathrm{Xe}$ was attributed to its being a mixture of isotopes.

There were three papers on the triple point of water. G. T. Furukawa et al. (NBS, USA) reported standard deviations of $8 \mu \mathrm{K}$ for measurements conducted over 4 or 5 days, testing before each measurement that the ice mantle was free to move on a slight tilting of the cell. (The well-known rotational impulse test may not assure the mantle to be free from slight sticking to the thermometer well.) High quality cells should be essentially free of air; a residual air pressure of $130 \mathrm{~Pa}$ causes about $0.01 \mathrm{mK}$ lowering of the triple point. Of the 21 cells that were compared, 3 cells which increased the spread of the triple points from 0.05 to nearly $0.2 \mathrm{mK}$ were considered substandard. J. Ancsin (NRC, Canada) presented results on the melting curves of water at the triple point and at one-atmosphere pressure of air, $\mathrm{0}_{2}, \mathrm{He}, \mathrm{Ar}, \mathrm{CH}_{4}, \mathrm{Kr}$, $\mathrm{Xe}$, and $\mathrm{CO}_{2}$ in sealed cells. A linear relation was obtained between the liquidus points of the ice and the solubility of the above substances. The results showed that a pressure of one atmosphere lowers the melting point by $7.3 \mathrm{mK}$. J. V. McAllan (CSIRO, Australia) reported that a pressure of one atmosphere of air lowers the melting point by $7.474 \pm 0.01 \mathrm{mK}$ and that the difference between the air-saturated ice point and the triple point is $9.85 \pm 0.1 \mathrm{mK}$. 
Three papers concerned with the triple point of gallium were presented. B. W. Mangum (NBS, USA) discussed triple-point measurements of $10 \mathrm{Ga}$ cells prepared using samples from three sources. Three of the cells were all plastic, while the other seven cells were stainless steel coated with Teflon wherever $G a$ was in contact. The triple points of the three all-plastic cells were found to be within a band of $0.04 \mathrm{mK}$; when the seven stainless steel cells were included, the band widened to $0.23 \mathrm{mK}$. The lower values obtained for the steel cells were attributed to contamination by the steel through pin holes in the Teflon. The average $\mathbf{G a}$ triplepoint temperature obtained with five SPRTs on the sample of highest purity in an all-plastic cell was given as $29.77398 \pm 0.00014^{\circ} \mathrm{C}$.

M. V. Chattle (NPL, UK) et al. presented results of the comparison measurements obtained at three laboratories (NPL, INM, and IMGC) on the triple points and melting points of three $\mathrm{Ga}$ cells, one furnished by each of the laboratories. The Ga samples in the NPL and INM cells were 99.9999 percent pure, while the sample in the IMGC was 99.99999 percent pure. Two SPRTs were used at each of the laboratories, one SPRT calibrated at the NPL and the other locally calibrated. The overall average temperature of each cell, as determined by the three laboratories, agreed to within $0.19 \mathrm{mK}$. The IMGC cell, with the purer sample, tended to give higher values. The average triple-point temperature of the three cells was found to be $29.77373^{\circ} \mathrm{C}$; the freezing point was on the average $1.98 \mathrm{mK}$ lower.

lower.

B. N. Oleinik et al. (Mendeleyev Res. Inst. Metrol., USSR) submitted a paper on the realization of the melting point of approximately 99.997 percent pure gallium. The melting-point temperature obtained using three SPRTs, was $29.7704 \pm 0.0004{ }^{\circ} \mathrm{C}$ (or $29.7724{ }^{\circ} \mathrm{C}$ for the triple point).

Several papers were presented on fixed points suitable for biomedical applications. J. D. Cox et al. (NPL, UK) described different techniques for realizing the triple points of water, phenoxybenzene, 1,3-dioxolan-2-one, and n-icosane in which they obtained standard deviations of the means of $0.2,0.2,0.5$, and $0.5 \mathrm{mK}$, respectively. The "outer solid-sheath method" with sample solidified on the outer cell walls was preferred for realizing the triple point, instead of solidifying the sample around the thermometer well and then obtaining an "inner melt".

M. E. Glicksman (Rensselaer Polytechnic Institute, USA) et al. described a technique for zone-refining succinonitrile to a purity estimated to be at lease 99.9996 percent. The measurements of its triple-point temperature were shown to be reproducible to $\pm 0.1 \mathrm{mK}$. The triple-point value reported was $\mathbf{5 8 . 0 8 0 5}$ $\pm 0.004{ }^{\circ} \mathrm{C}$.
J. M. Figueroa et al. (NBS, USA) presented a paper on measurements of the triple point of $R \mathbf{b}$. A calibrated bead-type thermistor was used for freezing and melting experiments of six cells containing nominally 99.9 percent pure $R b$. The value $39.265 \pm 0.014{ }^{\circ} \mathrm{C}$ was reported for the $\mathbf{R b}$ triple point. Freezing points of any given cell were found to be reproducible to $\pm 0.003^{\circ} \mathrm{C}$.

S. Sawada (NRLM, Japan) reported results of measurements of the triple-point temperature of In sealed in glass. Three samples of In ranging in purity from 99.999 to $99.9999 \%$ were investigated. From the measurements with three SPRTs, the triple-point value of $156.6296 \pm 0.0003{ }^{\circ} \mathrm{C}$ was obtained. In another paper, M. Hanafy (NIS, Egypt) et al. discussed meltingpoint measurements obtained with minature In cells containing about $70 \mathrm{~g}$ of In. The melting-point temperature obtained by using calibrated thermistors was reported to be $156.65 \pm 0.02^{\circ} \mathrm{C}$.

There were two Cd point papers. G. T. Furukawa et al. (NBS, USA) reported results of freezing-point measurements of five Cd cells prepared from two sample sources. They reported the cells to agree to within $\pm 0.1 \mathrm{mK}$ and they found the average freezing-point temperature, obtained with eight newly-calibrated SPRTs, to be $321.1082{ }^{\circ} \mathrm{C}$ (S.D. $=0.1 \mathrm{~m}^{\circ} \mathrm{C}$ ). The relatively broad range $\left(0.9 \mathrm{~m}^{\circ} \mathrm{C}\right)$ of the results was attributed to the possible presence of excess moisture in some of the mica-insulated SPRTs. The Cd point was stated to be useful in checking the calibration of SPRTs on the IPTS-68 to within $\pm 0.5 \mathrm{mK}$ and for detecting SPRTs of poor insulation resistance. J. V. McAllan et al. (CSIRO, Australia) presented results of monitoring the IPTS-68 calibrations of 43 thermometers of eight different designs at the $\mathrm{Cd}$ point, obtaining a value of $321.10814^{\circ} \mathrm{C}$ (S.D. $=0.71 \mathrm{mK}$ ) for the $\mathrm{Cd}$ freezing point. The authors found good-quality industrial platinum resistance thermometers (PRTs) with a temperature coefficient of resistance of $0.00385^{\circ} \mathrm{C}^{-1}$ to give temperature values at the $\mathrm{Cd}$ point to within $\pm 1 \mathrm{mK}$ of that determined with the IPTS standards.

J. V. McAllan (CSIRO, Australia) investigated the melting and freezing behavior of copper- $71.9 \%$ silver eutectic and of sodium chloride, using a PRT. The standard deviation of the mean melting point $\left(779.898^{\circ} \mathrm{C}\right)$ of the eutectic was $0.009^{\circ} \mathrm{C}$; that of the freezing point $\left(802.31^{\circ} \mathrm{C}\right)$ was $0.02{ }^{\circ} \mathrm{C}$.

Zhu Ci-Zhun (NIM, PRC) discussed the use of sealed freezing-point cells at high temperatures, sealed in order to avoid chemical contamination. Graphite crucibles containing the samples were sealed in fused-silica cells with an appropriate amount of Ar gas to give a pressure of $1 \mathrm{~atm}$ at the freezing point. Results showed the reproducibility of the plateau temperatures for $\mathrm{Sb}$ and $\mathrm{Cu}$ to be within 5 and $10 \mathrm{mK}$ to $20 \mathrm{mK}$, respectively. 
For optical pyrometry, blackbody cavities operate reliably near the gold point; above about $1800 \mathrm{~K}$, however, the operation of blackbodies becomes more difficult. A. Cezairliyan (NBS, USA) reviewed the use of the radiance temperature of metals at their melting points $(1800$ to $3300 \mathrm{~K})$ as possible high temperature reference points. For the measured radiance temperatures of $\mathrm{Fe}, \mathrm{Pd}, \mathrm{Ti}, \mathrm{Zr}, \mathrm{V}, \mathrm{Nb}, \mathrm{Mo}$, and $\mathrm{Ta}$, which range from about 1670 to $2846 \mathrm{~K}$, the average deviation ranged from $0.3 \mathrm{~K}$ for $\mathrm{Zr}$ to $1.2 \mathrm{~K}$ for $\mathrm{V}$. The need for additional work on the wavelength dependence of the radiance temperature was indicated.

The wire-bridge method for calibration of a thermocouple at the melting point of a metal, in which a short section of the pure metal joins the two legs of the thermocouple, is susceptible to errors from contamination of the metal by the thermocouple wires and permits only one measurement per "temperature sweep". M. Tischler et al. (INTI, Argentina) described a miniature graphite capsule sample holder of about $6 \mathrm{~mm}$ diameter and $12 \mathrm{~mm}$ length constructed with two external holes for insertion of thermocouple wires, suitable for repeated freezing- or melting-point calibrations of thermocouples. The graphite served to make the electrical contact between the wires. The inaccuracy of calibration obtained when using In, Sn, Cd, Pb, Zn, Sb, Al, Ag, Au, and $\mathrm{Cu}$ was estimated to be 0.2 or $0.3 \mathrm{~K}$.

D. Rappaport (Galai Laboratories, Ltd., Israel) discussed a novel method for realizing secondary temperature reference points. These reference points utilize the first-order phase transitions in ferroelectric or ferromagnetic solids which, as a result of the non-linear and abrupt changes in loss mechanisms, self-stabilize at the reference temperature under applied voltage or magnetic field. He has constructed reference points over the range from 300 to $500 \mathrm{~K}$, using the semiconductor/insulator phase transition in $\mathrm{Nd}$-doped $\mathrm{BaTi0}_{3}$. The devices are stable to 0.01 to $0.5 \mathrm{~K}$, depending upon construction details, and are useful for thermocouple and infrared pyrometer calibration.

F. Sakuma et al. (NRLM, Japan) described the design of a set of blackbody fixed points of $\mathrm{Cu}, \mathrm{Ag}, \mathrm{Al}, \mathrm{Sb}$, and Zn for calibration of narrow-band radiation thermometers using silicon-photodiode detectors. Metal samples of about $26 \mathrm{~cm}^{3}$ were contained in graphite crucibles. The estimated emissivity of the blackbody source was given as $0.999 \pm 0.0005$. The inaccuracy of realization of the blackbody fixed points was estimated to be $\pm 0.3 \mathrm{~K}$.

\section{Precision Platinum Resistance Thermometry}

Five papers were presented on the subject of precision platinum resistance thermometry, with three of them devoted to the design of high temperature thermometers and the behavior of those thermometers when heated for long periods of time at $1000^{\circ} \mathrm{C}$ and above.

R. J. Berry (NRC, Canada) presented results of studies of a reversible oxidation effect in PRTs operating in the temperature range from 0 to $630^{\circ} \mathrm{C}$. This effect is due to the formation and dissociation of a platinum oxide film on the surface of the $\mathrm{Pt}$ sensing element, which, he found, can cause changes in resistance ratios equivalent to as much as $24 \mathrm{mK}$. He outlined procedures for reducing temperature errors due to this effect in existing thermometers. Berry also discussed studies of the oxidation, stability, and insulation characteristics of Rosemount SPRTs.

H. J. Jung et al. (PTB, Berlin, FRG) reported results of a study of the stability of commercially-available hightemperature PRTs having a resistance of $5 \Omega$ at $0^{\circ} \mathrm{C}$. The authors found that during a 500-hour exposure of four thermometers to $1000^{\circ} \mathrm{C}$, two of the thermometers indicated temperature values at the silver point that stayed within a range of $30 \mathrm{mK}$.

J. P. Evans (NBS, USA) discussed results obtained with some high temperature PRTs employing resistors of various designs, including the single layer bifilar helix design. Each thermometer had a resistance of $2.5 \Omega$ at $0{ }^{\circ} \mathrm{C}$. The thermometers proved to be satisfactory in some respects but deficient in others when they were exposed to $1100^{\circ} \mathrm{C}$ for long periods. He also described a guarded-lead design that reduced the effects of electrical leakage when the thermometers were used at high temperatures.

Long Guang (Beijing Glass Res. Inst., PRC) et al. described precision high-temperature PRTs developed in China. The thermometer coil comprised a bifilar helix of $0.4 \mathrm{~mm}$ diameter $\mathrm{Pt}$ wire supported on a notched strip of quartz. The resistance of the thermometer at $0^{\circ} \mathrm{C}$ is 0.25 \&. Four such thermometers exposed to $1070^{\circ} \mathrm{C}$ exhibited drift rates in $R(0)$ which ranged from the equivalent of 0.5 to $-4.2 \mathrm{mK}$ per 100 hours at $1070^{\circ} \mathrm{C}$. Values of $W(100)$ ranged from 1.392536 to 1.392776 . The thermometers were reported to be mechanically durable and the silica sheath to be resistant to devitrification.

\section{Cryogenic Thermometry}

Five papers which were concerned with resistance thermometry at cryogenic temperatures were presented. P. R. Swinehart (Lake Shore Cryotronics, Inc., USA) discussed the properties of planar Ge thermometers and reported major advances in controlling As diffusion into Ga-doped Ge substrates. These planar Ge thermometers have a higher resistance than those of the bulk devices for a given sensitivity, but they are usable over a much 
greater temperature range. Also, electrical contacts are better on these planar thermometers than they are on the bulk devices. Both short-term and long-term stabilities were reported to be $\pm 0.5 \mathrm{mK}$ at $4.2 \mathrm{~K}$. Since these thermometers contain a p-n junction diode, they may be used as diode thermometers in the range from $100 \mathrm{~K}$ to $300 \mathrm{~K}$.

T. Shiratori (NRLM, Japan) et al. reported results of tests of some Pt-0.5 mol \% Co resistance thermometers, which were constructed as small and robust devices for industrial use over the temperature range from $\sim 4$ to $\sim 500 \mathrm{~K}$. They had an inaccuracy, including sensor interchangability and without calibration, of $\pm 0.5 \mathrm{~K}$ over the range given above when referenced to a common resistance-temperature relationship. For a three-point calibration $\left(0^{\circ} \mathrm{C}, 77.3 \mathrm{~K}\right.$ and $\left.4.2 \mathrm{~K}\right)$, individual thermometers were reported to have a $0.1 \mathrm{~K}$ inaccuracy above $16 \mathrm{~K}$.

Two papers were concerned with carbon-glass thermometry. B. W. Ricketson ICryogenic Calibrations, Ltd., UK) et al. presented results of cycling carbon-glass thermometers between room temperature and $77 \mathrm{~K}$. Some thermometers were reported to be stable to $\pm 5 \mathrm{mK}$ at $77 \mathrm{~K}$ over 30 cycles. Accuracies of fitting calibration data were determined and reported for different fitting procedures. With a fourth- or fifth-order polynomial, rms deviations of $0.5 \mathrm{mK}$ were obtained in the range of 1.5 to $16 \mathrm{~K}$. A tenth-order polynomial fitted the data from 1.5 to $300 \mathrm{~K}$ to about $\pm 5 \mathrm{mK}$ in the range from 16 to $300 \mathrm{~K}$ and to about $\pm 0.5 \mathrm{mK}$ in the range from 1.5 to $16 \mathrm{~K}$.

Yao Quanfa (Shanghai Institute of Process Automation Instrumentation, PRC) et al. described their construction of carbon-glass thermometers and reported results of reproducibility tests of some of them. They obtained reproducibilities ranging from \pm 0.3 to $\pm 2.1 \mathrm{mK}$ at $4.2 \mathrm{~K}$, when the thermometers were thermally cycled between 4.2 and $90 \mathrm{~K}$. The low values of magnetoresistance obtained were reported to be in agreement with results reported by other workers.

R. L. Rusby (NPL, UK) reviewed the performance of Rh-Fe thermometers over a period of several years and reported the abilities of different equations and fitting procedures of accurately representing the calibration date of the thermometers. He reported that over 8.5 years the largest apparent shift among the thermometers at $20 \mathrm{~K}$ was $0.35 \mathrm{mK}$. He presented results of fitting data from calibrations at 13 points $(6$ points between the lambda point and the normal boiling point of ${ }^{4} \mathrm{He}$, the $\mathrm{Pb}$ point, and another 6 points between 13.8 and $20.3 \mathrm{~K}$; or the latter 6 points being replaced by points at $13.8,17.0,20.3 \mathrm{~K}$, plus another 3 points between 24.56 and $26 \mathrm{~K}$ ) with a 7 th-order power series for 25 thermometers, showing that the fits were within $1.2 \mathrm{mK}$ of the calibration obtained over the entire range using many more points. Based on these results, he proposed that the Rh-Fe thermometer be considered for the next IPTS as the interpolating instrument to be used between the $\mathrm{Pt}$ thermometer range and the helium vapor pressure range.

In the general field of cryogenic thermometry, L. G. Rubin (MIT, USA) et al. presented a comprehensive review covering the period from 1969 through 1981. The review concentrated on work done in the temperature range from 1 to $\sim 100 \mathrm{~K}$. The areas covered by the review were temperature scales; fixed points and vapor pressure thermometry; gas thermometry; resistance and diode thermometry; thermoelectric, capacitance and noise thermometry; nuclear quadrupole resonance, quartz crystal frequency, ferrite permeability, magneto-resistance and superconducting thermometers; environmental effects; and instrumentation, methods and materials. The paper has a bibliography of 406 references.

E. R. Pfeiffer et al. (NBS, USA) reported results of a comparison of three realizations of the EPT-76, as derived from the NBS 2-20 K Scale, the NBS version of the IPTS-68 and the NPL version of the EPT-76 (transferred by means of calibrated $\mathrm{Rh}-\mathrm{Fe}$ thermometers). The authors concluded that the EPT-76 is non-unique by about $1 \mathrm{mK}$ at several points over its $0.5 \mathrm{~K}$ to $30 \mathrm{~K}$ range.

H. Armbruster et al. (Texas A\&M Univ., USA) presented designs of and procedures for constructing and using a gold/superconductor (e.g., $\mathrm{Nb}$ ) thermocouple to measure temperatures between $20 \mathrm{mK}$ and $9 \mathrm{~K}$. The authors found that the sensitivity of the thermocouple is much better than that of carbon resistance thermometers and that its resolution is about $2 \mu \mathrm{K}$ at $20 \mathrm{mK}$.

\section{Industrial Platinum Resistance Thermometers}

One session of the symposium, consisting of six papers, was devoted to a discussion of results obtained from studies of industrial PRTs. Papers on this subject were long overdue since, although such thermometers are widely used, there is a paucity of published information about them. Work on the behavior of industrial PRTs which was reported included studies of their thermal hysteresis and stress effects as a function of their design, the reproducibilities of general and specially. designed thermometers, the calibration characteristics and the equations required to fit their resistancetemperature behavior, and their possible use in high temperature resistance thermometry.

J. Severson presented a paper for D. J. Curtis, de- 
ceased, (Rosemount, Inc., USA) which described his investigation of thermal hysteresis of industrial PRTs due to thermal stresses introduced in different designs. Curtis found that the measured hysteresis, proportional to the temperature span, was consistent with a theory in which thermal stresses played the dominant role. Element designs which minimize hysteresis errors were developed and presented.

B. W. Mangum et al. (NBS, USA) reported the results of an investigation of the stability of 60 small industrial PRTs from 5 manufacturers upon thermal cycling from 0 to $\sim 250{ }^{\circ} \mathrm{C}$. Most of the thermometers underwent calibration drifts and showed effects due to the presence of moisture. Fifty percent of the thermometers had changes in $R_{o}$ greater than the equivalent of $0.015^{\circ} \mathrm{C}$ and $25 \%$ had changes greater than the equivalent of $0.05^{\circ} \mathrm{C}$. Generally, no improvement was found in the stability of the resistance ratio, $R(t) / R_{o}$, over that of the resistance itself.

The paper by N. M. Bass (CSIRO, Australia) described techniques for assembling industrial PRTs which can operate in the temperature range from 0 to $500{ }^{\circ} \mathrm{C}$ with an uncertainty of $\pm 0.02^{\circ} \mathrm{C}$, using both ceramic encapsulated $\mathrm{Pt}$ wire sensors and $\mathrm{Pt}$ film on ceramic substrate sensors which are commercially available. He gave a detailed prescription for the cleaning and assembly of such a thermometer. Two critical aspects of the construction are (1) the heating of the sensors and the assemblies in an open-ended fused-silica tube at $500{ }^{\circ} \mathrm{C}$. for 24 hours under a stream of dry $0_{2}$ provided by the boil-off from a Dewar of liquid oxygen, and (2) a $0.5 \mathrm{~mm}$ diameter hole in the four-pin plastic socket inserted in the top of the fused-silica sheath, which allows air to be drawn into the thermometer on each cooling cycle so that all internal components remain oxidized.

J. J. Connolly (CSIRO, Australial presented results on the stability, upon heating up to $250^{\circ} \mathrm{C}$ for 24 to 100 hours, and on the resistance-temperature relation of 87 industrial PRTs $(67$ of which originated from a single manufacturer) obtained during routine calibrations in the range from 0 to $250^{\circ} \mathrm{C}$. Since the manufacturer of the 67 thermometers takes great care to dry components during assembly, his thermometers have had many hours at $500{ }^{\circ} \mathrm{C}$ prior to being received for calibration. For these short-term stability measurements, Connolly found that the industrial PRTs were sufficiently stable and predictable for measuring temperatures to an uncertainty of about $\pm 10 \mathrm{mK}$ up to at least $250^{\circ} \mathrm{C}$. This uncertainty refers to the equivalent temperature difference between the experimental value and the fitted value of the resistance ratio, using the IPTS-68 equations. A cubic term in the equations gives a better fit.

J. V. McAllan (CSIRO, Australia) discussed results of his investigation of 26 industrial ceramic-based PRTs, prepared from sensors from 6 manufacturers as described by N. M. Bass, except that McAllan heated all of his sensors for about 100 hours at $800^{\circ} \mathrm{C}$ under a slow stream of dry oxygen. He found that such thermometers could have practical applications in routine laboratory measurements to inaccuracies of $0.1 \mathrm{~K}$ at temperatures up to $960{ }^{\circ} \mathrm{C}$ and that, with care, difference measurements could be made to $0.02 \mathrm{~K}$ at $960{ }^{\circ} \mathrm{C}$. McAllan found that the departures at the AI point from the IPTS-68 equation, obtained by calibration at the triple point of water, $99^{\circ} \mathrm{C}$, and the $\mathrm{Zn}$ point, depended more on construction details than on wire purity. He believes that although the thermometer scale provided by such instruments may not agree with that of the purest $\mathrm{Pt}$, the departures for many sensors will be less than $0.05 \mathrm{~K}$ at temperatures up to $660^{\circ} \mathrm{C}$ and may not be much worse up to $960^{\circ} \mathrm{C}$. They might thus serve as an inexpensive and convenient way for transferring a temperature scale to another laboratory with an inaccuracy of less than $\pm 0.05 \mathrm{~K}$.

A. Actis et al. (IMGC, Italy) presented results of an investigation of 27 wire-wound industrial PRTs from 6 manufacturers. The thermometers were calibrated over the temperature range from -200 to $420{ }^{\circ} \mathrm{C}$. The authors tried fitting several different interpolating equations to the data and found that alumina-insulated thermometers, constructed such as to have their coils partially free to expand and contract, required three calibration points, in addition to that at $0{ }^{\circ} \mathrm{C}$, in order to reduce uncertainties to within $\pm 0.01{ }^{\circ} \mathrm{C}$ over the range from 0 to $420{ }^{\circ} \mathrm{C}$. For the range from -100 to $200^{\circ} \mathrm{C}$, the range in which the biggest demand for precision temperature measurements is concentrated, they found that a quadratic equation with a deviation function could provide temperatures with uncertainties within $\pm 0.015^{\circ} \mathrm{C}$, if suitable correction terms were applied below $0^{\circ} \mathrm{C}$.

\section{Automatic and Precision Resistance Thermometry}

A session on automatic and precision resistance thermometry contained papers by a number of individuals (and companies) who have long been active in the resistance thermometry field, and have recently developed new, high-precision bridges based on microprocessor technology. These new bridges are similar in that they may be easily interfaced with desk calculators and mini-computers, but are most remarkable not for their similarities but rather for their radically different modes of operation.

C. G. M. Kirby (NRC, Canada) described an automatic resistance thermometer bridge that closely resembles a manual instrument described by the same 
author at the fifth temperature symposium in 1971. His circuit uses several high-input-impedance operational amplifiers provided with isolated power supplies, in conjunction with a precision inductive divider. The bridge operates with a $30 \mathrm{~Hz}$ sine-wave excitation, and although it is presently configured to make use of a commerical desk-top calculator for all bridge functions, an earlier model was developed that used a dedicated microprocessor chip. The author claimed that the direct use of a desk-top calculator provides significant advantages in cost and flexibility.

R. D. Cutkosky (NBS, USA) described two automatic resistance thermometer bridges for new and special applications. These are additions to a family of bridges of which the first member was described in the 1980 Conference on Precision Electromagnetic Measurements. The instruments, which use 15 or $30 \mathrm{~Hz}$ square-waves and a special five-stage transformer, rely upon a dedicated microprocessor and an intricate timing algorithm to achieve a high degree of freedom from electrical interference. The instruments are claimed to be accurate to one part in $10^{7}$ of reading, with a least count of $1 \mu$.

P. C. F. Wolfendale et al. (Automatic Systems Laboratories, Ltd., UK) described a new line of highprecision resistance bridges for resistance thermometry. These bridges make use of three-stage transformers in which the excitation current is provided by feedback amplifiers, causing their input impedances to be so high that they can be connected directly across the resistances under test. This scheme has been used by others in $400 \mathrm{~Hz}$ bridges, but these authors have chosen to operate at $3 / 2$ times the line frequency to reduce frequency-dependent errors and for interference rejection. In practice, this means either a 75 or $90 \mathrm{~Hz}$ operation. The stabilization of a feedback amplifier under these conditions is not a simple matter. The authors appear to have devoted a great deal of effort to this problem, and have developed a circuit that could be useful for a number of other applications.

N. L. Brown et al. (Neil Brown Instrument Systems, Inc., USA) described a new automatic resistance thermometer bridge. This instrument appears to be very flexible with many self-checking features. As with the other instruments described above, it makes extensive use of transformers and feedback amplifiers. A number of original circuits are contained in this instrument, including a binary inductive divider with low-impedance solid-state switching. The instrument is capable of very high precision, and is designed to operate at $384 \mathrm{~Hz}$, which is remote from most power line harmonics, and is, in addition, a good choice for circuits which combine transformers and feedback amplifiers.

\section{Time Response}

Time response is an important parameter of thermometry where accurate measurements of rapidly varying temperatures are required. In a session on the time response of thermometers, T. M. Dauphinee (NRC, Canada) reviewed temperature measurements that are obtained simultaneously with salinity (conductivity) and pressure measurements in ocean environments. The measurements require short response times with only a few $\mathrm{mK}$ error in order to obtain an accurate profile of the ocean. Cable considerations require the use of a single wire for both power and signal, with cable armor and/or sea return. The design of thermometers of $\mathrm{Pt}$ and $\mathrm{Cu}$ wires with 8 to $250 \mathrm{~ms}$ response times was described. For faster response (a few $\mathrm{ms}$ ), the application of thermistors and multi-junction thermocouples was discussed. For improving the accuracy of measurements, techniques were given for measuring the resistance differences between the thermometer and the reference resistor. Electronic circuitry for measurements using ac excitation was also described.

T. W. Kerlin (Univ. of Tenn., USA) et al. described two methods for evaluating the time response of installed thermometers. In the first method, from measurements of the thermometer response at two or more fluid flow conditions, the intrinsic response that is independent of the fluid condition as well as the surface response that depends on the fluid conditions are determined. The response of the thermometer in other fluids is then estimated from heat transfer correlations for the fluids. In the second method, the time response is estimated by measuring the transient response of the installed thermometer as the excitation current is applied or removed. This response is analyzed to predict the response of the thermometer to a change in fluid temperature.

P. J. Giarratano et al. (NBS, Boulder, USA) discussed the design and performance of a thin $\mathrm{Pt}$ film as both heater and thermometer for transient heat transfer measurements. Procedures for vapor-depositing $\mathrm{Pt}$ films on both surfaces of a quartz disk of $0.15875 \mathrm{~cm}$ thickness were given. Two calibrations of the $\mathrm{Pt}$ films in the range from 76 to $293 \mathrm{~K}$ showed about \pm 1.0 percent change for one film and \pm 0.5 percent change for the other film. The response time at $77 \mathrm{~K}$ was shown to be about $0.1 \mathrm{~ms}$. The measured thermal conductivity of the quartz substrate was shown to be in satisfactory agreement with published values.

R. M. Carroll et al. (ONRL, USA) described the construction of Type $\mathrm{K}, \mathrm{Mg} 0$-insulated, sheathed thermocouples and their response times under various conditions. The response time of an insulated-junction, Type 304 stainless steel-sheathed thermocouple of $1.6 \mathrm{~mm}$ 
diameter was reduced 50 percent when the tip diameter was reduced 8 percent by swaging. When the thermocouple wires were "side-welded" to the stainless-steel sheath, the response time was reduced by about $90 \%$. When a thermowell is used, the response time is governed principally by the well. To reduce the response time, the use of a good thermal conductor is recommended for filling the space between the well and the thermocouple.

D. Linenberger et al. (NBS, Boulder, USA) presented results of investigations of the response-time at 4,76 , and $295 \mathrm{~K}$ of thermometers which included $\mathrm{Ge}$ resistance thermometers, carbon resistors, diodes, and a silicon-on-sapphire resistance device. The technique involved measurement of the thermal response of a thermometer to changes in self heating when a step change was made in the excitation current. At $4 \mathrm{~K}$, time constants of less than $1 \mu$ s seem to be possible. Measurements were made in both gas and liquid phases of He at $4 \mathrm{~K}$ and of $\mathrm{N}_{2}$ at $76 \mathrm{~K}$. The time constants were found to be nearly the same for the two phases of $\mathrm{He}$, to be larger for gaseous $N_{2}$ than for liquid $N_{2}$, and to be larger at $76 \mathrm{~K}$ than at $4 \mathrm{~K}$ (e.g., the increases in $\mathrm{N}_{2}$ gas compared to those in $\mathrm{He}$ gas were 100 to 180 times for carbon resistors, about 1.5 times for carbon-fiber resistors, about 100 times for $G e$ resistors, about 140,000 times for silicon-on-sapphire resistors, and 30 to 14,000 times for diodes).

\section{Electronic, Nuclear and Ultrasonic Thermometry}

Developments of various types of temperature-related properties for thermometry, employing specialized circuitry and electronics, were discussed in the session on electronic thermometry. K. P. Shambrook (Doric Scientific, USA) reviewed the application to temperature measurements of thermocouples, metal resistance thermometers, thermistors, and diodes. The discussion included problems of connecting the sensors to readout instruments, signal conditioning, common-mode and normal-mode noise, noise rejection, multiplexing, cabling, and thermocouple reference junction compensation. For the instruments, methods of linearization of the signal were described. Advantages of analog and digital readout were compared.

A. Ohte et al. YYokogawa Electric Works, Ltd., Japan) described the features and the performance of a fully-antomatic, precision nuclear quadrupole resonance (NQR) thermometer which is based upon the temperature dependence of the NQR absorption frequency of ${ }^{35} \mathrm{Cl}$ nuclei in $\mathrm{KClO}_{3}$. The thermometer was calibrated over the temperature range from 90 to $398 \mathrm{~K}$ on the IPTS-68 at the NBS and the NQR frequency ob- tained as a function of temperature was accurately fitted by a 10th-degree polynomial. Since the ${ }^{35} \mathrm{Cl}\left(\right.$ in $\mathrm{KCl}_{3}$ ) NQR frequency-temperature relation is an inherent property of $\mathrm{KClO}_{3}$, the thermometer serves as an excellent transfer standard and never needs recalibration. Also, other samples of pure $\mathrm{KClO}_{3}$ have the same $\mathrm{NQR}$ frequency-temperature relationship and can be used without calibration. The authors found that the overall thermometer uncertainty, including that from probe interchangeability, reproducibility of absorption frequency, and frequency-temperature conversion using a polynomial approximation, was $\pm 1 \mathrm{mK}$ over the range from 90 to $398 \mathrm{~K}$.

A. Ohte et al. (Yokogawa Electric Works, Ltd., Japan) described the development and performance of precision silicon-transistor thermometers. These are mass-producible electronic thermometers using inexpensive transistors as the temperature sensors. These thermometers are based on the propery of transistors that their base-emitter voltage decreases with increasing temperature. The authors reported reproducibilities of $\pm 0.02{ }^{\circ} \mathrm{C}$ during a 1037 -day test in which the sensors were cycled between room temperature and $125^{\circ} \mathrm{C}$. With the use of a novel linearizing circuit, different sensors required only a one-point temperature calibration to give linearities within $\pm 0.1{ }^{\circ} \mathrm{C}$ over the temperature range from -50 to $125^{\circ} \mathrm{C}$. By using a more accurate linearizer and a three-point temperature calibration, the linearity can be improved to $\pm 0.01^{\circ} \mathrm{C}$. There are some special high-temperature transistors which are suitable for use over the range of -75 to $200^{\circ} \mathrm{C}$. A variety of sensors, differently packaged, were assembled and assessed. With the advantages of small size, high accuracy and low cost, it is expected that these thermometers will find wide application in medical electronics, chemical and biological laboratories, agriculture, meteorology, and oceanography.

H. A. Tasman et al. (Commission of the European Communities, Joint Research Center, Karlsruhe Establishment, FRG) reviewed the developments and operating experiences of ultrasonic thin-wire thermometry for nuclear applications. The predominant method is that of using the pulse echo. The authors found that thoriated tungsten sensors were stable for short periods of time at temperatures above $2600^{\circ} \mathrm{C}$, e.g., they observed no change in calibration during a $1 / 2$ hour test at $2860^{\circ} \mathrm{C}$. An error of less than $30^{\circ} \mathrm{C}$ was obtained when fuel-rod centerline temperatures at 2400 to $2450^{\circ} \mathrm{C}$ were monitored for 378 hours, and also when a clean environment at $2000{ }^{\circ} \mathrm{C}$ without fuel was monitored for 2000 hours. Although the thin-wire ultrasonic thermometer remains a complicated tool with occasional unsatisfactory reliability, it can provide 
temperature profile data from environments where all other methods fail. The main difficulties are caused by interactions between the sensor and its protecting sheath.

L. C. Lynnworth (Panametrics, USA) reviewed thermometry using pulsed interrogation of multi-zone waveguides. He reported that, although some advances have been made in the theory and interpretation of test data, the greatest progress has been made in the application of this technique. The most important applications are in the temperature range from 2000 to $3000^{\circ} \mathrm{C}$.

M. G. Rao (Univ. of Southampton, UK) presented a brief review of the use of semiconductor junctions as eryogenic temperature sensors. Silicon, germanium and gallium-arsenide junctions were discussed. $\mathrm{He}$ indicated areas in which silicon-diode thermometers are being widely used.

\section{Noise Thermometry in Industrial Envlronments}

The subject of Johnson-noise thermometry in industrial environments was summarized by T. V. Blalock (Univ. of Tenn., USA) et al. The authors reported that most workers in noise thermometry employ a modification or extension of the noise-voltage-ratio method of Garrison and Lawson, while a few use noise power obtained from measurements of noise voltage and noise current, to determine Johnson-noise temperatures. They reviewed the theoretical foundation for Johnson-noise thermometry, gave a survey of several basic methods of noise thermometry which use conventional electronic signal processors, presented some applications of noise thermometry to temperature-scale metrology (e.g., at IMGC and CSIRO), and discussed some applications in process temperature instrumentation. They concluded that the progress in noise thermometry in the past 10 years was due to rapid improvements in signal-processor components and to the increased availability and power of digital computation.

H. Brixy (KFA-Jülich, FRG) et al. have applied Johnson-noise thermometry, using noise-voltage ratios and correlation methods, to nuclear reactors and industrial processes as high as $1150^{\circ} \mathrm{C}$. The authors claimed high reliability and accuracy even after long periods of operation in such environments.

M. C. Decreton ICEN/SGK Nuclear Research Center, Belgium) has employed a modified Jahnsonnoise-power method for measurement of temperatures up to $1500^{\circ} \mathrm{C}$, with a $0.3 \%$ agreement with thermocouple temperature indications, in tests conducted in temperature-regulated ovens. Niobium-shielded, alumina-insulated $\mathrm{Pt}$ and $\mathrm{Re}$ probes were used in those tests. A 10-second integration time per measurement was used.

T. R. Billeter (EG\&G Idaho, Inc., USA) et al. presented results of a comparison involving hightemperature measurements obtained by using Johnsonnoise thermometry and thermocouple thermometry. The temperature sensor consisted of W-Re thermocouple elements terminated in a Re coil, the latker serving as the noise-thermometer sensor. Comparisons made at temperatures up to $1500^{\circ} \mathrm{C}$ generally showed agreement to within $4 \%$ of the readings. Nonthermal noise was a severe problem at temperatures above $1500^{\circ} \mathrm{C}$.

M. Imamura et al. (Yokogawa Electric Works, Ltd., Japan) reported on the development of an automatic commercial prototype Johnson-noise thermometer with an inaccuracy of $\pm 0.3 \%$ from 77 to $1235 \mathrm{~K}$.

T. V. Blalock (Univ. of Tenn., USA) et al. discussed the results of a Johnson-noise-power thermometer which was developed and applied to measurement of temperatures from 400 to $1770 \mathrm{~K}$ in nuclear reactors and to in-situ calibration of PRTs in nuclear power plants. For measurements of temperature and resistance in the temperature range from 273 to $1000 \mathrm{~K}$, the uncertainties were within $\pm 0.5 \%$ of the readings $199 \%$ confidencel for sensing resistors of 50 to $300 \Omega$, using cables as long as $18 \mathrm{~m}$.

The major accomplishments of the above authors are the analysis and implementation of Johnson-noise thermometry systems over a wide temperature range, the virtual elimination of effects of spurious non-thermal-noise errors, and the applieation of Johnson-noise thermometry to temperature-scale metrology and to industrial conditions beyond the reach of conventional thermometers. The major problems discussed were the need to enlarge bandwidths and extend integration times to reduce uncertainties to the level ( 1 part in $10^{6}$ ) achieved by other precision thermometers, problems with long cables, and effects of dielectrics in Johnsonnoise thermometer sengors at high temperatures.

\section{Thermocouples}

Three sessions of the symposium were devoted entirely to the properties, performance, and applications of thermocouples. An enormous amount of work has been conducted in this area of thermometry.

Eight papers were presented that dealt with varions aspects of the use and evaluation of nicrosil/nisil thermocouples. G. W. Burns (NBS, USA) reviewed experimental work on nicrosil/nisil thermocouples conducted since 1971, and discussed the present status of the use, availability, and standardization of the thermocouple in the United States. He concluded that 
nicrosil/nisil can be a valuable addition to the family of letter-designated thermocouples.

N. A. Burley (MRL, Australian Department of Defence) et al. reported results of a joint investigation by MRL and NBS on the thermoelectric stability and the oxidation-resistance of nicrosil and nisil on the addition of $\mathrm{Mg}$ beyond their nominal composition. The oxidationresistance and the thermoelectric stability of nisil were found to be enhanced as a direct function of initial $\mathbf{M g}$ concentration in the range investigated, which was from 0.08 to $0.21 \mathrm{wt}$. \%. There was also evidence of enhanced oxidation-resistance achieved by adding $\mathbf{M g}$ to nicrosil, but no enhancement of thermoelectric stability was observed. Also, N. A. Burley et al. (MRL) presented a critical quantitative comparison of the properties and thermoelectric stability of the nicrosil/nisil thermocouple with those of letter-designated base-metal thermocouples.

T. P. Wang et al. (AMAX Specialty Metals Corp., USA) discussed thermoelectric stability data obtained for Type $K$ and nicrosil/nisil thermocouples used in production furnaces operating in air and in reducing atmospheres at temperatures ranging from 500 to $1180^{\circ} \mathrm{C}$. It was found that, in general, the emf stability of nicrosil/ nisil thermocouples was at least two to three times better than that of Type $K$ thermocouples.

R. L. Anderson et al. (ORNL, USA) presented a paper on the thermoelectric stability of metal-sheathed thermocouples of various diameters $(0.5$ to $3 \mathrm{~mm})$. Nickelbased thermocouples (Type $K$ and nicrosil/nisil) with various combinations of sheath materials, such as Type 304 stainless steel and Inconel-600, were tested to determined the rate and extent of decalibration due to heating for various periods of time (for as long as about 1200 hours) at temperatures ranging from 600 to $1200{ }^{\circ} \mathrm{C}$. Similar tests were also run at temperatures as high as $1350{ }^{\circ} \mathrm{C}$ with small diameter $(0.5 \mathrm{~mm})$, compactedMg0-insulated, Type S and Type B thermocouples that had various sheath materials, including stainless steel, Inconel, and various $\mathrm{Pt}-\mathrm{Rh}$ alloys. The results showed that the sheathed thermocouple is a complex system at elevated temperatures and that the thermoelements tend to become contaminated by the diffusion of materials from the sheaths through the insulation. It was found that the decalibration of nickel-based thermocouples was more severe in stainless-steel sheaths than in Inconel sheaths. Also, it was found that the small-diameter Type $\mathrm{S}$ thermocouples sheathed in either $\mathrm{Pt}-10 \% \mathrm{Rh}$ or Pt$20 \%$ Rh tubing exhibit stability and reproducibility comparable to larger-diameter, bare-wire Type $S$ thermocouples at temperatures up to at least $1200^{\circ} \mathrm{C}$.

E. H. McLaren et al. (NRC, Canada) presented results of extensive studies carried out on various noble- and base-metal thermocouples and on their individual thermoelements at temperatures in the 0 to $1100{ }^{\circ} \mathrm{C}$ range. Type $S$, Type $K$, and nicrosil/nisil thermocouples, as well as various $\mathrm{Pt}-\mathrm{Rh}$ alloys, were included in the studies. The thermocouples and thermoelements were tested in metal-freezing-point cells in different temperature gradients, after they had been subjected to various thermal and mechanical treatments. Inhomogeneous oxidation was found to have a significant effect in the long-term degradation during service of both noble- and base-metal thermocouple alloys. The noblemetal thermocouples were reported to be much more homogeneous than the base-metal thermocouples.

A. Thurlbeck (UK Atomic Energy Authority) discussed the design and development of Type $K$ thermocouples for measurements of coolant and fuel temperatures up to $850^{\circ} \mathrm{C}$ in a gas-cooled nuclear reactor, and of W-Re thermocouples for measurements of fuel temperature up to $1500^{\circ} \mathrm{C}$. He presented results showing the reliability of those thermocouples during their 5 years of operation. He also described the use of some metal-sheathed nicrosil/nisil thermocouples for measuring the temperature of fuel-rod cladding during a brief in-pile experiment.

C. A. Mossman et al. (ORNL, USA) presented some methods of testing for thermocouple inhomogeneities and described the use of an inhomogeneity test system as a diagnostic tool to evaluate temperature measurement errors due to inhomogeneities.

In addition to these presentations on thermocouple thermometry, several authors discussed thermocouple performance and properties. R. L. Anderson et al. (ONRL, USA) presented results of thermal-cycling tests with metal-sheathed, compacted-Mg0-insulated, Type K thermocouples of small diameter $(0.5 \mathrm{~mm})$. Experiments were conducted to determine the relative effect of differential thermal expansion, wire size, grain size, and manufacturing technology on the performance and reliability of thermocouples sheathed in stainless steel and in Inconel. They found that repeated heating and cooling of the sheathed thermocouples between 350 and $805^{\circ} \mathrm{C}$ led to failure in the thermcouple wires by fracturing of the wire along grain boundaries embrittled by the formation of metal oxides. They also found that with smaller initial grain size in the thermoelement wire, the operating life was increased.

R. P. Reed (Sandia National Laboratories, USA) discussed diagnostics for validation of thermocouple data in applications in which thermocouples are used in hostile environments. The diagnostics include measurements of loop resistance, noise voltage, and circuit isolation and they reveal the occurrence, location, and nature of thermocouple failure. Reed also presented 
a functional model of thermoelectric thermometry which can be used to reveal problems in complex circuits and allows a direct evaluation of errors.

D. D. Pollock (SUNY, Buffalo, USA) proposed a simplified spin-cluster mechanism to explain the thermoelectric properties of $\mathrm{Ni}$ and some of its alloys near their Curie temperatures. This mechanism is based primarily upon the temperature dependence of the electrons involved in the clusters.

J. Ohno et al. (Nippon Steel Corporation, Japan) described a differential thermometer developed for measurement of high-temperature combustion gases at temperatures of about $2000^{\circ} \mathrm{C}$. The temperatures of the gases are calculated by fitting the response curve of the thermocouple to temperatures up to about $1200^{\circ} \mathrm{C}$. Inaccuracies of about $1 \%$ were claimed.

Y. Kawate et al. (Kobe Steel, Ltd., Japan) described a technique for measuring the thickness of a blast furnace lining, and thus its erosion. The technique involved the use of a multiple thermocouple sensor, with several Type $K$ thermocouples in the sheath and insulated from each other. This permitted the simultaneous measurement of temperature variations at a number of positions across the lining. By analyzing the signals obtained, an inaccuracy of less than $5 \%$ was obtained in the estimates of the lining thickness.

There were several presentations giving results of studies of thermocouples designed for use in nuclear reactors. S. C. Wilkins (EG\&G, USA) discussed the development of small-diameter $(0.3$ to $0.7 \mathrm{~mm})$ metalsheathed thermocouples (both W-Re and Type K) for accurate and reliable measurement of the surface temperature of nuclear-fuel-rod cladding. He discussed fabrication and attachment techniques for such measurements and gave details of material compatibility.

C. P. Cannon (HEDL, USA) presented a paper on the fabrication and evaluation of metal-sheathed W-Re alloy thermocouples designed for measuring nuclear-reactor fuel-centerline temperatures as high as $2200^{\circ} \mathrm{C}$. W $-5 \%$ $\mathrm{Re} / \mathrm{W}-26 \%$ Re thermocouples, insulated with $\mathrm{HfO}_{2}$ tubing and sealed hermetically within a $1.6 \mathrm{~mm}$ diameter Re sheath, were found to undergo changes in emf output of less than $2 \%$ during out-of-pile tests run for 1000 hours at $2200^{\circ} \mathrm{C}$.

P. Siltanen (Imatran Voima Oy, Finland) et al. described their experiences with metal-sheathed Type $K$ thermocouples used for measuring inlet and outlet reactor-core cooling-water temperature in a pressurized water reactor. The thermoelectric properties of inlet, but not outlet, thermocouples were found to be influenced by radiation, in proportion to the reactor power level. This was assumed to be the result of neutron reactions in the thermocouple wires.

R. W. McCulloch et al. (ORNL, USA) discussed results of an investigation in which they thermally cycled thermocouples. The authors gave criteria for the improvement in the lifetimes of $0.5 \mathrm{~mm}$ diameter metalsheathed Type $K$ thermocouples, used in nuclear-fuelrod simulators to measure high temperatures $\left(1200^{\circ} \mathrm{C}\right)$ and to follow severe thermal transients (up to $50^{\circ} \mathrm{C} / \mathrm{s}$ ). They found that improvements could be achieved in the reliability of such thermocouples by using better annealing schedules and better drawing techniques during the fabrication of the devices.

\section{Thermistors}

One session of the symposium, comprising five papers, was devoted entirely to thermistors. In that session, J. M. Zurbuchen et al. (Yellow Springs Instrument Co., Inc., USA) discussed the aging phenomena inherent in the multi-grain, multi-phase $\mathrm{NiMn}_{2} \mathrm{O}_{4}$ systems used in thermistors. Based on their observations, the authors concluded that aging, manifested as thermometric drift, is due to changes in the crystal structure of the material and to non-equilibrium degree of inversion.

T. H. LaMers et al. (Yellow Springs Instrument Co., Inc., USA) presented a paper on enhanced stability achieved for a recently-developed glass-coated, interchangeable disk thermistor. Results obtained during 2500 hours of aging at temperatures ranging from -80 to $250^{\circ} \mathrm{C}$ indicate that the stability of these units is significantly better than that of uncoated interchangeable disks and is comparable to that of glasscoated bead thermistors.

M. Sapoff et al. (Thermometrics, Inc., USA) presented the results of an investigation to evaluate the exactness of fit of third-degree polynomials to the resistancetemperature relationship of thermistors. Seventeen different thermistor materials were evaluated over the temperature range of -80 to $260{ }^{\circ} \mathrm{C}$. Analysis of the data indicated that the expression

$$
\ln R_{T}=A o+A_{1} / T+A_{2} / T^{2}+A_{3} / T^{3}
$$

was valid, to within measurement uncertainties, for temperature spans of $100^{\circ} \mathrm{C}$ between -80 and $30^{\circ} \mathrm{C}$, spans of $150^{\circ} \mathrm{C}$ between -60 and $260^{\circ} \mathrm{C}$, and spans of $200^{\circ} \mathrm{C}$ between 0 and $260^{\circ} \mathrm{C}$.

R. L. Berger et al. (NIH, USA) described the design and construction of thermistors with response times of $5 \mathrm{~ms}$. The authors also described a fast, low-noise, ac bridge with digital temperature output. They presented a computer technique for analyzing the thermal response of the thermistor and reaction vessel, yielding values 
which compared favorably with their experimental results.

R. E. Wendt (Zurheide-Herrman, Inc., USA) presented a technique for tailoring the characteristics of perovskite-type oxide thermistors. By combining powders which exhibit different switching temperatures and controlling their relative distribution, he demonstrated that it is possible to obtain a log-linear characteristic over a relatively wide temperature range. Data were presented for a system comprising equal weights of six powders having rated switching temperatures evenly spaced from 15 to $115^{\circ} \mathrm{C}$.

\section{Plosmo Thermometry}

In a session on plasma thermometry, the emphasis was on measurements of the very high temperatures of magnetically-confined fusion-type plasmas. P. C. Efthimion et al. (Princeton Univ., USA) and F. J. Stauffer (Univ. of Md., USA) discussed the measurements of "temperatures" in the range from a few hundred to a few kilo-electron volts $\left(10^{6}\right.$ to $\left.5 \times 10^{8} \mathrm{~K}\right)$ in tokamaks, using electron-cyclotron resonance and emission-spectral-line Doppler-broadening techniques. These two new techniques were compared with other more established methods, such as Thomson laser scattering, and were found to agree quite well. Each of the two newlydeveloped methods offers unique features, such as timeresolved measurements over the entire length of the pulsed plasma discharge for the electron-cyclotron technique, and measurement of ion, rather than electron, temperatures for the Doppler-broadening technique.

D. H. Nettleton (NPL, UK) discussed the use of a wall-stabilized arc plasma as a radiometric standard. Using spectroscopic methods, the temperatures were measured to an uncertainty of less than $1 \%$ at approximately $14,000 \mathrm{~K}$, thus allowing the emission from this plasma to be used as a radiometric standard.

\section{Fast Radiation Thermometry}

This was the first time in the history of the Temperature Symposia that an entire session was devoted to "fast radiation thermometry", "fast" meaning millisecond or shorter time-resolution. This indicates a definite increase in interest in rapid temperaturemeasurement techniques in the high-temperature region, both in connection with thermophysical-properties measurements and in specific high-temperature applications, such as gas turbines, high-temperature gases, and gas and dust explosions.

An accurate two-color microsecond-resolution pyrometer was described by G.M. Foley et al. (NBS,
USA). This pyrometer was constructed in connection with a capacitor-discharge system for the measurement of thermophysical properties of substances at high temperatures. The pyrometer is capable of temperature measurements at $1.5 \mu$ intervals in the range from 2000 to $6000 \mathrm{~K}$, with a signal resolution of about $0.1 \%$.

Development of a submicrosecond-resolution muitiwavelength pyrometer at the European Institute for Transuranium Elements was described by J. -F. Babelot (EITE, FRG) et al. This pyrometer also was built in connection with thermophysical-properties measurements at high temperatures utilizing a laser pulse technique. The time-resolution of the pyrometer was reported to be $10 \mathrm{~ns}$ and the spatial resolution was stated to be about $100 \mu \mathrm{m}$.

A summary of research occurring over the last 10 years at the Instituto di Metrologia "G. Colonnetti" was presented by F. Righini et al. (IMGC, Italy). The main emphasis was on millisecond-resolution pyrometry, which was developed in connection with thermophysicalproperties measurements. The successful use of silicon photodetectors was discussed, and characteristics and performances of the fast pyrometers were presented.

In relation to applications to temperature measurements of gas and dust explosions, K. $L$. Cashdollar et al. (Bureau of Mines, USA) described the use of a rapid-scan spectrometer which has a wavelength range of 1.7 to $4.8 \mu \mathrm{m}$ and a maximum rate of 800 scans/s. Also in this connection, multi-wavelength infrared pyrometers having about $20 \mu$ s response times were described.

Application of radiation thermometry to the development and control of gas turbine engines was described by T. G. R. Beynon (Land Pyrometers, Ltd., UK). The radiation thermometers that were used could operate in ambient temperatures from -60 to $550^{\circ} \mathrm{C}$ under $30 \mathrm{~atm}$ pressure and continuous vibration. Their response times were a few microseconds.

The development of a packaged, automated instrument for temperature measurements in hightemperature gases based on the emission-absorption technique was described by S. A. Self et al. (Stanford Univ., USA). It employs optical fibers to transmit radiation from a standard lamp to the gas, and from the gas to a detector. The time-response of the instrument is $1 \mathrm{~ms}$, and the instrument is intended for temperature measurements in the range from 2000 to $3000 \mathrm{~K}$.

\section{Optical Pyrometry}

J. L. Gardner et al. (CSIRO, Australia) described the design and construction of a broadband, ratio optical pyrometer using silicon photodiode detectors. Design 
considerations included the use of two closely spaced wavelengths at short wavelengths in order to minimize effects of variations in the emissivity with wavelength. Measurements with blackbody sources in the range from 600 to $900{ }^{\circ} \mathrm{C}$ in the region of $0.85 \mu \mathrm{m}$ showed deviations from thermocouple readings of about $3^{\circ} \mathrm{C}$. The results were less satisfactory when the oxidation state of the surface was changing.

Jiang Schichang et al. (Shanghai Inst. of Process Automation Instrumentation, PRC) discussed the investigation of the calibration characteristics of the components of optical pyrometer systems. The relation between the mean effective wavelength and other properties of the detector and filter was investigated. The procedure for calibration of silicon photodiodes in the range from 700 to $1200^{\circ} \mathrm{C}$ was described.

F. Sakuma et al. (NRLM, Japan) described a $900 \mathrm{~nm}$ narrow-band optical pyrometer system, with a siliconphotodiode detector, for establishing a temperature scale by calibration at blackbody fixed points in the range from 420 to $2000{ }^{\circ} \mathrm{C}$. A quadratic relation that was fitted to the calibration data of the pyrometer system at the $\mathrm{Al}, \mathrm{Ag}$, and $\mathrm{Cu}$ points yields a temperature scale estimated to be accurate to $\pm 0.5^{\circ} \mathrm{C}$.

B. Woerner (Inst. for Nuclear Energy, Stuggart University, FRG) presented a paper on the application of a special vacuum-photocell detector and electronic instrumentation to a standard optical pyrometer to obtain high linearity between measured radiance and output signal. Comparison measurements with standard optical-pyrometer techniques showed the photocell pyrometer to agree to within $0.1 \mathrm{~K}$ with tungsten strip lamps at temperatures up to $2500 \mathrm{~K}$ and to within $0.1 \mathrm{~K}$ with blackbody sources at temperatures up to $1700 \mathrm{~K}$.

\section{Applied Radiation Thermometry}

One session was devoted entirely to applied radiation thermometry in the steel industry. The papers presented there described state-of-the-art techniques being introduced for temperature measurement and control of various processes in steel mills.

K. Tamura et al. (Kawasaki Steel Corporation, Japan) discussed the improved calibration procedures for radiation pyrometers used in their facilities. The uncertainty in the calibration was estimated to be less than $\pm 2{ }^{\circ} \mathrm{C}$.

J. E. Roney (Jones \& Laughlin Steel Corporation, USA) discussed a technique used to compensate for the error caused by high levels of background radiation from flames, heating tubes, and hot walls of a processing furnace. He described three different configurations, each tailored to solve a specific measurement problem. In each configuration, two similar pyrometers are used.
The first pyrometer is aimed directly at the surface of the steel of unknown temperature. Depending on the configuration, the second pyrometer is aimed at a target of known emissivity and/or temperature which has been placed within the furnace. From the difference between the two signals, the temperature of the hot steel surface can be determined. A measurement equation for the "dual pyrometer" method and some sample calculations which showed the effects of various sources of error were presented.

T. Iuchi et al. (Nippon Steel Corp., Japan) presented two methods for the simultaneous measurement of the temperature and the emittance of steel in processing furnaces. The technique is particularly useful in processes where both temperature and emittance of the source may change continuously during the measurement. Examples discussed included measurement and control of the temperature of a continuous annealing furnace for steel sheet and of a coating process for steel sheet.

Y. Tamura et al. (Sumitomo Metal Industries, Ltd., Japan) discussed two developments in the measurement of the temperature of steel in a reheating furnace. The first development involved the use of a water-cooled sight tube fabricated from castable ceramic. The second development was a heat-resistant data logger which tolerated exposure to $1200^{\circ} \mathrm{C}$ for up to 4 hours. The logger could read thermocouple voltages at pre-selected time intervals and the readings were stored in a memory module within the logger. In an example of its application, thermocouples were fixed at various locations on a steel slab. The logger was placed on the slab and the assembly passed through a furnace. The timetemperature data subsequently retrieved from the logger were found to be very useful in analyzing the control and performance of the reheating furnace.

T. Yamada et al. (Nippon Kokan, Ltd., Japan) described a microcomputer-based camera employing a self-scanning silicon-photodiode linear array to measure and record temperature distributions on hot rolled products. Typical temperature distributions at various locations along the process line for rolled sheet and for $\mathrm{H}$ shaped steel were presented.

J. Ohno (Nippon Steel Corp., Japan) discussed a new method for the determination of the temperature distribution within the field of view of a radiometer. This is based on the measurement of multi-spectral radiance. A typical application might be the determination of the temperature of a metal joint during a welding process.

\section{Emissivities and Blackbody Furnaces}

In a session on emissivities and blackbody furnaces, A. Ono (NRLM, Japan) presented results of a Monte 
Carlo calculation of the apparent emissivities of cylindrical cavities with conical bottoms for which it was assumed that the cylindrical surfaces were diffuse and the conical surfaces were partially specular. He showed that apex angles of the cone near $60^{\circ}, 90^{\circ}$, and $180^{\circ}$ should be avoided because successive specular reflections on the cone can considerably reduce the apparent emissivity. He showed the advantage of choosing $120^{\circ}$ as the apex angle in that a mirror-like conical bottom of that angle guides incident radiation onto the darkest part of the cavity by specular reflection. Thus, a higher degree of specularity gives a higher apparent emissivity. Consequently, by making a conical surface more specular, a perfect blackbody can be approached even if the conical surface is not black.

A. Ono (NRLM, Japan) et al. also presented results of their evaluation of the apparent emissivities of lateral holes formed on a Ta tube, determined both experimentally, by the integral blackbody method, and theoretically, by a Monte Carlo analysis. The apparent emissivities were determined experimentally by extrapolating the radiances of different-sized lateral holes to a view factor of zero, the condition at which the hole would be a perfect blackbody. The calculated apparent emissivities agreed with the experimental observations to within their uncertainties. The effects on the cavity quality of temperature distribution along the tube were also investigated.

S. Hattori et al. (NRLM, Japan) reviewed a new concept of an effective temperature to express the radiant characteristics of non-isothermal blackbody cavities. The effective (spectral) emissivity has been frequently used in the past as a quantity to express radiant characteristics of isothermal and non-isothermal cavities but this quantity explicitly depends on the wavelength of the radiation and on the temperature through the Planck relation for blackbody spectral radiance. Therefore, effective emissivities must be calculated for every wavelength and temperature associated with the radiation thermometers to be calibrated. The effective temperature of the cavity, however, depends neither on the wavelength of the radiation nor on the temperature of the cavity to a first-order approximation of temperature differences within a cavity. It depends only on the temperature distribution. The effective temperature can be regarded as the true temperature of the cavity. Beyond the first-order approximation, the author developed an empirical equation, taking into account the strong non-linear behavior of blackbody spectral radiance, which provides approximate effective temperatures accurate to better than $5 \%$ when the temperature distributions along the cylindrical axes are depressed by up to $10 \%$ at the apertures.

Zhu Yingsong (Shanghai Institute of Process Automa- tion Instrumentation, PRC) et al. described the design, construction, and operation of two cylindro-conical heatpipe blackbodies operating in a horizontal position over the temperature ranges from -50 to $50^{\circ} \mathrm{C}$ and from 40 to $150{ }^{\circ} \mathrm{C}$, respectively. The cavities are $6.0 \mathrm{~cm}$ in diameter and $30.0 \mathrm{~cm}$ long and are open to the atmosphere. One of the heat-pipe blackbodies is an ammonia/stainless-steel heat pipe which operates between -50 and $50^{\circ} \mathrm{C}$; the other is a water/copper heat pipe which operates in the range from 40 to $150^{\circ} \mathrm{C}$. Using the water/copper heat pipe, the authors obtained a temperature uniformity of $\pm 0.03{ }^{\circ} \mathrm{C}$ over a $20.0 \mathrm{~cm}$ length from the cone apex in the temperature region from 110 to $150^{\circ} \mathrm{C}$. In the region of 40 to $110^{\circ} \mathrm{C}$, they obtained a uniformity of $\pm 0.06{ }^{\circ} \mathrm{C}$. For the ammonia/stainless-steel heat pipe, they obtained uniformities of $\pm 0.01{ }^{\circ} \mathrm{C}$ in the region of -20 to $50{ }^{\circ} \mathrm{C}$ and $\pm 0.02{ }^{\circ} \mathrm{C}$ in the range from -20 to $-40^{\circ} \mathrm{C}$. They reported calculations that showed that the total effective emissivities of the conical part and of about four-tenths of the cylindrical part adjacent to the cone were greater than 0.999 .

\section{Spectroscopic Thermometry}

Optical diagnostic techniques in which molecular vibrational and rotational populations are measured to determine temperature were discussed in two sessions entitled "Temperature Measurements in Hot Gaseous Media." Molecular-energy-level populations (mainly vibrational and rotational levels) are determined in "real time" (down to $10 \mathrm{~ns}$ ) with fine spatial resolution las small as $1 \mathrm{~mm}^{3}$ ) by these non-contact methods.

Optical absorption and Raman spectroscopy, especially the non-linear optical technique of coherent antiStokes Raman spectroscopy (CARS) are now finding very practical application. For example, J. P. Taran et al. (Office National d'Etudes et de Recherches Aérospatiales, France), G. L. Switzer et al. (System Research Laboratories, Inc., USA), J. W. Fleming et al. (NRL, USA), J. F. Verdieck et al. (United Technologies Research Center, USA), L. A. Rahn et al. (Sandia National Laboratories, USA), and D. Klick et al. (Ford Motor Co., USA) discussed CARS thermometry in six presentations, giving results of investigations involving such practical applications as the study of well-stirred chemical reactors, hydrogen plasmas, laboratory "model" flames, jet engines, and internal-combustion engines. The study of internal-combustion engines received a good deal of attention, with presentations on this subject by L. A. Rahn and by D. Klick. The ability of the optical techniques to yield spatial and temporal temperature distributions is of great importance in such 
work. M. C. Drake et al. (General Electric, USA) and P. P. Yaney et al. (Univ. of Dayton, USA) presented papers in which they described the application of conventional Raman spectroscopy to temperature measurement, with an emphasis on the study of turbulent combustion and mixing.

R. W. McCullough (Aeronautical Research Associates of Princeton, Inc., USA) et al. discussed the use of $\mathrm{OH}^{-}$ absorption for "real time" (to $10 \mathrm{kHz}$ ) temperature (spatially-averaged) measurements in a hypersonic propulsion test facility. H. G. Semeriian (NBS, USA) et al. presented a paper on the novel technique of optical tomography and its use in determining in "real-time", full spatial maps of inhomogeneous temperature fields.

The importance for accurate thermometry of a complete characterization of the fundamental molecular parameters which determine an observed optical spectrum was emphasized in two papers-one by C. C. Wang (Ford Motor Co., USA), dealing with $\mathrm{OH}^{-}$absorption, and the other by M. C. Drake, dealing with linear (and to some extent non-linear) Raman spectroscopy. An accurate knowledge of molecular properties is required in order to achieve overall accuracies more closely commensurate with the reported precisions. In many cases, the systematic errors in these techniques lead to uncertainties which are 5 to 10 times larger than the random error. At the present time and under the best of conditions, measurement imprecision of the order of $\pm 10 \mathrm{~K}$ can be achieved for temperatures averaged over $1 \mathrm{~s}$ to $10 \mathrm{~s}$, in the 1000 to $3000 \mathrm{~K}$ region. Single-shot temperature measurements $(10 \mathrm{~ns}$ to $10 \mathrm{~ms})$ generally have relative imprecisions of 4 to $8 \%$ in this temperature range.

As another application of optical methods to thermometry, L. J. Bowie (Evanston Hospital, USA) described some spectroscopic techniques for measuring the temperature of liquids in cuvettes of analytical instruments, with particular application to clinicallaboratory instruments. The principle involved is the coupling of some temperature-dependent physical or chemical property of a fluid (e.g., viscosity or $\mathrm{pH}$ ) to a spectral change which is sensitive to that same property. These techniques can be easily used to determine thermal equilibration times in absorption- or luminescencedependent photometric devices. The use of suitablycalibrated materials permits the measurement of temperatures in cuvettes, which are otherwise generally inaccessible, with uncertainties of $0.1{ }^{\circ} \mathrm{C}$ or better. Through the use of this technique, Bowie and his colleagues have shown some commonly-used clinicallaboratory analyzers to have serious defects in temperature control and in the accuracy of the claimed temperature of reactions.
In a session on Biological and Human-Comfort Thermometry, J. Edrich (Univ. of Colorado, USA) et al. reviewed principles and techniques of microwavethermography imaging of subcutaneous temperature distributions at $1 \mathrm{~cm}$ and $3 \mathrm{~cm}$ wavelengths. So far, this method uses comparison techniques in the detection of tumors, e.g., in the detection of breast cancer. This technique is currently being used in clinical tests as a diagnostic tool for the detection of cancer.

E. Mayer (Fraunhofer-Institut für Bauphysik, FRG) described the instruments and the methods used in studies of human thermal environments and of human comfort. The instruments used were a resultant-surfacetemperature meter, a scanning radiometer, an airtemperature meter, a relative-humidity meter and an airflow probe. Measurements obtained with these instruments permitted the calculation of an equivalent ideal temperature, a directional radiated heat loss, a directional skin temperature and directional heat flows.

An interesting paper, although somewhat removed from the theme of this symposium, was given by $T$. $H$. Benzinger (NBS, USA) who discussed a theory of the thermodynamics of living matter which permits the thermodynamic treatment and understanding of the multiple functions of living matter, the genetically-coded macromolecules of proteins, polynucleotides and membranes, their weak interactions and reversible conformational changes at moderate temperatures. The GibbsHelmholtz equation is inadequate in this regard in that it is incomplete. The complete equation for chemical equilibrium was given as

$$
-R T \ln K(T)=\Delta H_{\mathrm{o}}^{\mathrm{o}}-\left[\underset{\mathrm{o}}{\mathrm{T}} \frac{\Delta C_{p}^{\mathrm{o}}\left(T^{\prime}\right) \cdot d T^{\prime}}{\mathrm{T}^{\prime}}-\int_{\mathrm{o}}^{\mathrm{T}} \Delta C_{\left.p^{\mathrm{o}}\left(T^{\prime}\right) \cdot d T^{\prime}\right]}\right.
$$

Through the use of this equation, Benzinger showed, as examples, that one can explain the experimental results on the unfolding of a protein and the unwinding of a polynucleotide double helix, results that cannot be explained through the use of the Gibbs-Helmholtz equation.

\section{Fluidic, Self-Diffusion and Eddy-Current Thermometry}

Several papers were presented on the application of the properties of gases for thermometry. R. M. Phillippi (HDL, USA) et al. described the application of capillaryflow properties of gases to thermometry. The change in gas pressure with change in capillary flow caused by temperature change was amplified using fluidic pressure 
amplifiers to a level where commercial pressure transducers could be activated. The upper temperature limit is governed by the melting point of the refractory material used for the capillary. Tests with various capillary materials and gases up to $2500{ }^{\circ} \mathrm{C}$ gave an estimated inaccuracy of about one percent.

The self-diffusion coefficient of a gas is related to the $3 / 2$ power of the absolute temperature. M. Lamvik (ITV, Norway) described the application of self diffusion to thermometry. An equation was derived for the case of diffusion of helium in hot nitrogen gas for the temperature range from $1000 \mathrm{~K}$ to $5000 \mathrm{~K}$.

K. Sano et al. (Nippon Kokan, Ltd., Japan) discussed results of an investigation which used induced eddy currents for temperature measurement of steel plates. The primary coil was operated at $25 \mathrm{kHz}$ and the eddycurrent field was detected by two secondary coils. Test measurements between room temperature and $70^{\circ} \mathrm{C}$ with the steel plate in a water bath showed good linearity (about \pm 1 or $\pm 2{ }^{\circ} \mathrm{C}$ ) between the eddy-current output and the temperature. Steel samples of different permeability show different eddy-current outputs.

\section{Automation}

The automation of precision measurements has resulted in new techniques for measurements as well as new measurement instruments and systems. Automation of precision measurements requires considerable care beyond the simple recording of data, and consideration must be given not only to the performance of the automated instrumentation, but also to the design of the measurement method and to the structuring of the computer software. The following papers described some of the techniques, instrumentation and control circuitry that have been employed to successfully obtain precision measurements.

M. H. Cooper et al. (ORNL, USA) discussed the redundancy and self-checking techniques that they have developed to insure that measurements are equal in reliability and accuracy to those obtained with manuallyoperated laboratory potentiometers. Cognizance of the manner in which digital instruments operate is required so that the computer software programs can be structured to include self-checking techniques for the quantities that are measured, and the use of external standards for checking the accuracy of the automated instruments must be built into the measurement process. The measurement of additional physical parameters of sensors is often easily accomplished with automation, and the authors demonstrated the usefulness of measuring thermocouple-loop resistance in order to gain further insight into thermocouple performance.

C. G. M. Kirby (NRC, Canada) described the conver- sion of a calibration facility, formerly operated manually, to a system under computer control. Instrumentation requirements for automation, the construction of inexpensive digitally-controlled current sources for thermometers and digitally-controlled power supplies for stirred liquid baths, and controls for tube furnaces were described. Measurements are made by minimizing the rate of change of temperature rather than attempting to control to an exact temperature, and thermometer selfheating effects are determined for each thermometer under test.

C. T. Van Degrift et al. (NBS, USA) discussed the software and hardware architecture and performance of an automatic control and calibration system for lowtemperature measurements. Provisions are made for the scheduling of complex combinations of measurement and control tasks in a versatile manner by the easy establishment of task sequences with definable macro commands, so that many different experiments in different laboratories can be quickly structured. The authors have applied their techniques to $\mathrm{Ge}, \mathrm{Rh}-\mathrm{Fe}$, and $\mathrm{Pt}$ thermometry, and to tunnel-diode oscillators to sense temperature, pressure, dielectric constant and magnetic susceptibility.

\section{Temperature Control and Calibration}

In the area of temperature control, T. M. Kegel et al. (Univ. of New Hampshire, USA) discussed work on fluidic preamplifiers and fluidic power amplifiers to control the temperature of a combustion chamber, employing a feedback linearizing scheme for the power amplifier. Thus, all components in the furnace control are pneumatic.

Zhang Jipei et al. (Shanghai Institute of Process Automation Instrumentation, PRC) described a furnace for the comparison-calibration of PRTs of various types at temperatures up to $700{ }^{\circ} \mathrm{C}$ with uncertainties of 2 to $5 \mathrm{mK}$. The furnace is interesting in that one of the heaters is wound directly on the $\mathrm{Cu}$ temperatureequalizing block in which the thermometers are inserted, and the thermometer for temperature control is a $\mathrm{Pt}$ wire wound close to the heater on the surface of this block.

C. A. Busse et al. (Commission of the European Communities, Joint Research Centre, Italy) discussed the use of inert-gas-controlled heat pipes to obtain stable isothermal heat zones in furnaces over the range from 20 to $1100^{\circ} \mathrm{C}$. Details of heat pipe construction, gas pressure control, working fluids, and furnace design were presented.

Wang Zhensen (Shanghai Institute of Process Automation Instrumentation, PRC) described a very interesting compound thermometer, consisting of a $\mathrm{Pt}$ wire 
in series with a $\mathrm{Rh}-\mathrm{Fe}$ alloy wire, which enables them to obtain a sensitive and fairly linear response over the entire range from 4.2 to $300 \mathrm{~K}$. Using this, the temperature controller requires no other sensor for control. Details were provided for construction of the controller, which contains a simple ac sensing bridge utilizing an inductive-divider set-point.

H. El-Shammaa et al. (National Institute of Standards, Egypt) reported that they now have facilities for calibration of SPRTs in the temperature range above $0^{\circ} \mathrm{C}$. They are able to realize precisely the triple point of water and the freezing points of $\mathrm{Sn}$ and $\mathrm{Zn}$.

V. A. Chistyakov (Mendeleyev Res. Inst. of Metrology, USSR) et al. submitted a paper on the theoretical analysis of radiometer calibrations using blackbody sources. Procedural and instrumental errors were discussed.

\section{Conclusions}

In our attempt to summarize the Sixth International Symposium on Temperature, there were some papers of the symposium which were not covered, but it has been our aim to give the general flavor and content of the symposium and not to give a comprehensive or detailed review. This summary is no substitute for having attended the symposium or for obtaining the proceedings of the symposium when they are published.

There have been many significant accomplishments in thermometry during the 11 years since the fifth symposium on temperature and a revolution has occurred in electronic instrumentation. Significant advances in thermometry have been made throughout the entire temperature range. During the next decade, we undoubtedly will not only make many more significant advances in thermometry but a new IPTS is expected to be developed. The new Scale will probably be promulgated in 1987 or thereabouts. Reactions to and realizations of that Scale will likely dominate several sessions of the Seventh Temperature Symposium.

We gratefully acknowledge discussions with and the assistance given by many colleagues in our writing this summary. In particular, we want to thank G. W. Burns, A. Cezairliyan, R. D. Cutkosky, J. P. Evans, L. A. Guildner, W. S. Hurst, M. L. Reilly, J. R. Roberts, G. J. Rosasco, M. Sapoff, and R. L. Shepard. 